Chapter 2

\title{
Desalination of Industrial Effluents Using Integrated Membrane Processes
}

\author{
Marek Gryta \\ Additional information is available at the end of the chapter
}

http://dx.doi.org/10.5772/49993

\section{Introduction}

The term integrated or hybrid membrane processes refers to the integration of one or more membrane processes with or without the conventional unit operations in order to increase the performance depending on the type of feed and product quality required [1, 2]. A coupling of different membrane processes into the integrated systems allowed to develop the efficient technologies, which have been successfully used for water desalination and the treatment of industrial effluents [1-3]. The realization of these processes resulted in the production of fresh or process water. The most current techniques of desalination are thermal distillation and the membranes technology: electrodialysis (ED) and reverse osmosis (RO) [2].

The installation for the desalination of water and different effluents create a certain amount of the concentrates that must be disposed in an environmentally appropriate manner. Each year, a large amount of RO concentrates is discharged and leads to a significant loss of water resource and disposal challenge. In spite of the scale of this economical and environmental problem, the options for brine management for the inland plants are rather limited. These options include: discharge to surface water or wastewater treatment plants, deep well injection, land disposal, evaporation ponds, and mechanical/thermal evaporation [1-3].

The diluted solutions of salts are expensive for the treatment; therefore, in the case of industrial effluents they are often discharged directly into the environment. The discharges of such wastewater pose an environmental impact and cause an enhancement in the surface water salinity $[2,4]$. The separation of salt from aqueous solutions is carried out most fre- 
quently using the thermal methods, such as multi-stage flash evaporation (MSF). The thermal processes are based on improved distillation, evaporation and condensation technologies with the aim to save energy and to obtain fresh water with a low level of TDS and at lower operating costs. However, with regard to energy consumption, these processes are essentially used for the concentration of brines.

The thermal processes are generally more expensive than $\mathrm{RO}$, although a distillation method produces pure water independently on the quality and salinity of the feed water. Reverse osmosis can be employed for a preliminary concentration of saline wastewater, thus the cost of the thermal methods will be considerably reduced and the range of their application can include the diluted solutions. However, the RO process requires the application of a sophisticated pre-treatment due to the considerable problems associated with the fouling and scaling [2]. The applications of nanofiltration (NF) or ultrafiltration/nanofiltration (UF/NF) integrated system, to achieve the removal of the divalent ions, allows to limit the scaling phenomenon (mainly $\mathrm{CaSO}_{4}$ ) and the concentration factor in the $\mathrm{RO}$ process can be enhanced [2-5].

The effluents containing salts together with several organic substances, such as protein or polysaccharides, are generated during the realization of several industrial processes [2-6]. The biological methods are traditionally used for wastewater treatment. A high concentration of salt in wastewater possesses additional problems in its purification. Moreover, current and pending state regulations lower effluent discharge limits, therefore these methods cannot meet new restrictions. The best solution is realization the zero liquid discharge idea, which means that the industrial effluents are recovered as a clean stream for re-use, and the concentrate stream can be disposed off in an environmentally safety manner, or further reduced to solid $[2,4,6,7]$. The $R O$ concentrates can be treated with ED, which is capable of achieving a maximum concentrate of $80 \mathrm{~g} / \mathrm{L}$, and evaporators achieve a concentration of $300 \mathrm{~g} / \mathrm{L}$ [2].

The solutions containing the large amounts of salts can be concentrated using the membrane distillation (MD) [6-8]. This process has a potential application for the water desalination and the wastewater treatment $[6,9,10]$. The separation mechanism of the MD process is based on the vapour/liquid equilibrium of liquid mixtures. The volatile components of the feed evaporate through the pores of the membrane; therefore, the presence of the vapour phase in the pores is a necessary condition for MD [11, 12]. During the MD process of the solutions containing non-volatile solutes, only the water vapour is transferred through the non-wetted hydrophobic porous membrane, and the obtained distillate comprises high purity water. The MD process enables the production of pure water from water solutions, the quality of which impedes a direct application of the $\mathrm{RO}$ for this purpose [6, 7, 11-13].

In the direct contact MD variant (DCMD) the membrane separates the hot feed from the cold distillate (Figure 1). The driving force for the mass transport is a difference in the vapour pressures, resulting from different temperatures and the compositions of the solutions in the layers adjacent to the membrane [11, 14]. 


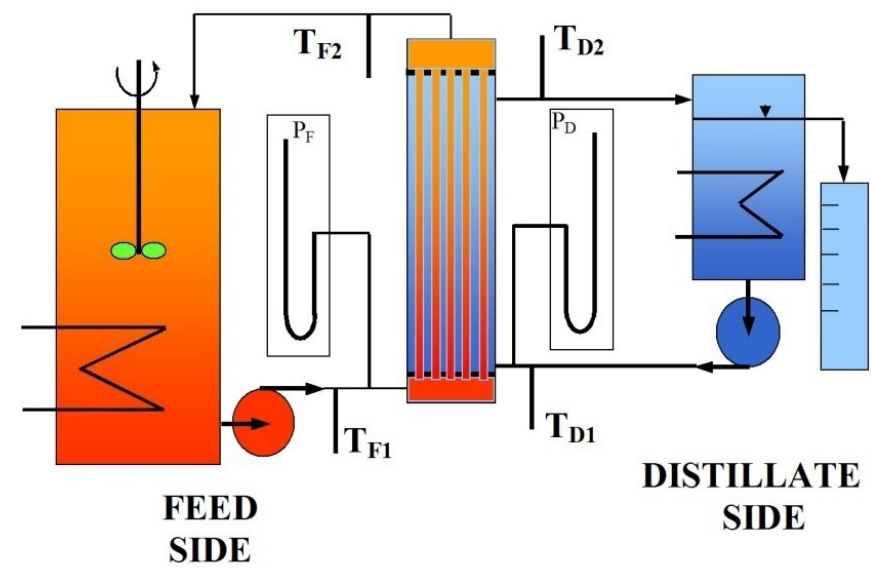

Figure 1. Experimental set-up of DCMD installation.

The treatment of saline wastewater can be performed utilizing the MD process to produce pure water and a concentrate containing the substances present in the parent solution. Subsequently, the components of this concentrate can be separated using the crystallisation of salt followed by the precipitation of dissolved substances $[7,8,14-16]$. This enables the disposal of such complex wastewater or their recycling. The obtained process water can be recycled for technological purposes.

The industrial use of the vacuum membrane distillation (VMD) to further concentrate the $\mathrm{RO}$ brines was proposed as a complementary process to seawater desalination [10]. Although, scaling occurs in VMD for high salt concentrations, its impact on the permeate flux was very limited. Large areas of the membranes remain free of visible fouling. The main salts responsible for the scaling are calcium crystals such as calcium carbonate and calcium sulphate, which have the lowest solubility. In order to reduce the scaling, the accelerated precipitation softening was integrated with direct contact membrane distillation, which establish a desalination process for high-recovery desalting of primary reverse osmosis concentrate $[7,17]$.

The integrated membrane processes were implemented in the industry for water re-use, therefore, the volume of discharged wastewater was significantly reduced [1, 2]. Moreover, the membrane technologies are presently an established part of several industrial processes. The use of membranes to separate and recover products and by-products from process streams may increase the process efficiency $[2,5,18,19]$. The possibility of application of integrated membrane systems, especially the MD process combined with crystallization, created one of the new possibilities to solve the saline wastewater treatment [14-17]. 


\section{Effluents concentration integrated with salt precipitation}

A problem associated with effluents management may results from two reasons: a) the generated solutions are of appropriate purity, but the concentration of solute is too low to find a practical application; b) a solution contains, besides desired components, also impurities which preclude its further utilization. In both cases, the concentration or treatment of effluents by traditional methods is generally unprofitable $[2,15]$. The concentration of such solutions by membrane processes, often in combination with the salt crystallization can be an advantageous alternative $[4,7,8]$.

The membrane technologies were used for processing a wide spectrum of feed streams containing salts in wide variety of applications. The implementation of integrated membrane systems appears an interesting possibility for improving desalination operations [2]. For example, the RO, NF and DCMD processes were used for the removal of boron and arsenic from water [20]. A serious problem is associated with the presence besides the ions such salts like $\mathrm{NaCl}, \mathrm{FeCl}_{3}$ or $\mathrm{CuSO}_{4}$ also the $\mathrm{Ca}^{2+}$ and $\mathrm{HCO}_{3}{ }^{-}$ions in the treated solutions. As a result, the precipitation of $\mathrm{CaSO}_{4}$ and $\mathrm{CaCO}_{3}$ can occurs during the separation of effluents [21]. It is referred as "scaling", and takes place in both membranes processes (Figure 2) and the heat exchangers (evaporators) installations [22].

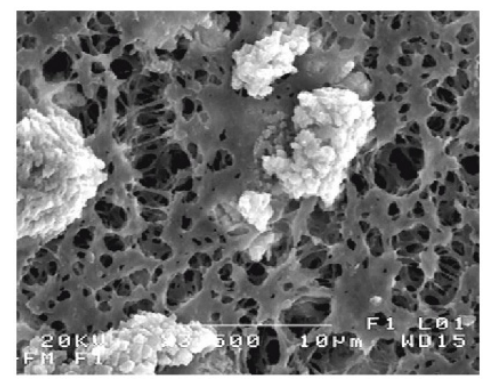

Figure 2. SEM image of $\mathrm{CaCO}_{3}$ deposit precipitated during MD process. Feed: tap water.

It was demonstrated that the induction times are significantly reduced if the precipitation take place in the presence of membranes, thus causing an increase of the $\mathrm{CaCO}_{3}$ nucleation rate [7]. However, the MD process is affected by bicarbonates dissolved in water, which undergo a decomposition reaction when feed is heated and the precipitation of carbonates on the membranes surface was observed [23-25]. As a consequence, during the first few hours of water desalination the $\mathrm{CaCO}_{3}$ deposit layer was formed on the membrane surface (Figure $3 \mathrm{~A})$. The deposit was significantly reduced by means of either feeding MD installations with water pretreated in an accelerator (softening and coagulation) [26] or by acidifying them up to $\mathrm{pH}=4$ [13]. Although the chemical coagulation followed by sand filtration or microfiltration decreases the fouling potential, a deposition of small amounts of precipitate on the membrane surface is still observed (Figure 3B). 
In the case of the membranes, the deposit is formed not only onto the surface, but also penetrates their pores interior, what may damage the membrane structure [21]. Such properties exhibit especially the crystals of gypsum $\left(\mathrm{CaSO}_{4} 2 \mathrm{H}_{2} \mathrm{O}\right)$ (Figure 4). The crystallites inside the membrane occupy the space significantly larger than the pore dimensions, what leads to a destruction of the membrane structure. The application of membranes that are significantly thicker than a layer of crystallizing salt allows to maintain the mechanical strength of the membranes and prevents the membranes from complete wetting during MD process.
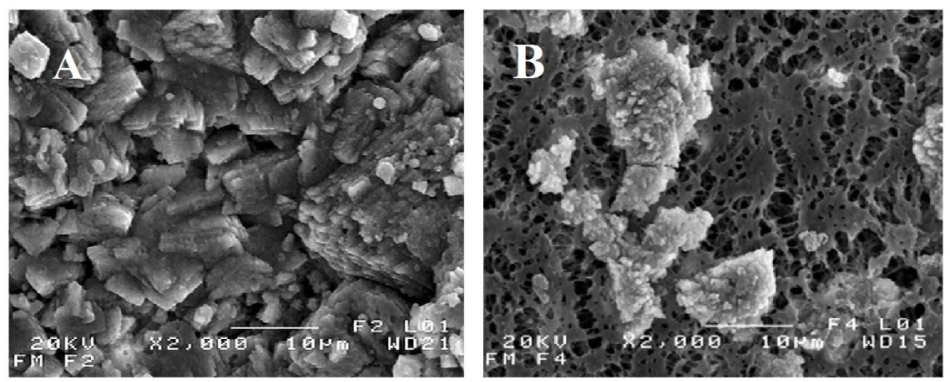

Figure 3. SEM images of deposit formed on the membrane surface during the water desalination by MD process. A) desalination of natural water, B) desalination of industrially pre-treated water (accelator).

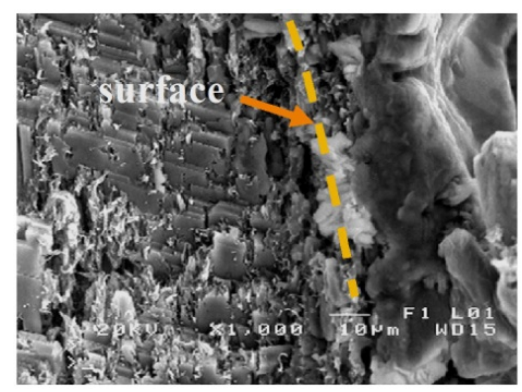

Figure 4. SEM image of membrane cross-section with $\mathrm{CaSO}_{4}$ deposit formed on the membrane surface during MD process of brackish water.

The formation of deposit during effluents desalination can be limited by adding antiscalant to the feed solutions. The application of polyphosphates as antiscalant restricted the amount of deposits formed on the membrane surface during the desalination of water by MD process. However, the morphology of deposit was changed, and an amorphous, low porous scaling layer was formed on the membrane surface instead of crystallites (Figure 5). As a consequence, a decline of MD process efficiency was larger in the case of antiscalant addition. This phenomenon increased along with increased antiscalant concentration [27]. Moreover, the industrial effluents often contain such large amounts of salts that a dosage of antiscalants would have to be very large, and their efficiency would be doubtful. 

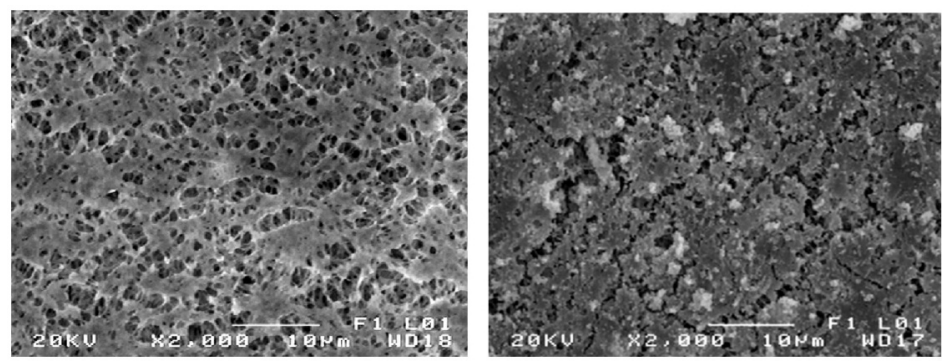

Figure 5. SEM images of Accurel PP S6/2 membranes. A) internal surface of new membrane; B) deposit formed on the membrane surface during MD process of tap water with $10 \mathrm{ppm}$ of $\left(\mathrm{NaPO}_{3}\right)_{\mathrm{n}}$.

Effluents desalination by membrane distillation can be restricted by solutes precipitation on the membrane surface, what resulted in a progressive decline of the permeate flux. In such a case there are two solutions: a) the crystals are formed on the membrane surface and they are systematically removed, or b) by using the integrated systems the formation of a scaling layer on the membrane surfaces is restricted, and the crystals formed in the solution subjected to the concentration are separated in the external devices such as net crystallisers [28-30].

In the last case, we stated that the membrane scaling could be limited by the salts precipitation (e.g. $\mathrm{CaCO}_{3}$ ) in a pre-filtration nets element assembled at the inlet of the MD module (Figure 6).

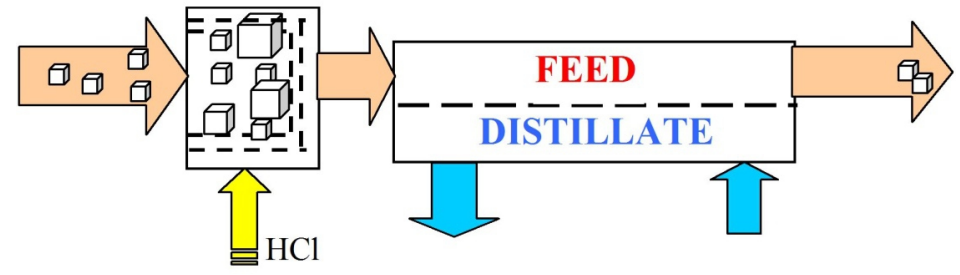

Figure 6. Desalination of effluents using the MD module connected with pre-filtration nets element.

The deposit precipitation (inside the pre-filter) eliminated the supersaturation state provided that the induction time of new crystals would be longer than the residue time of feed inside the MD module. The filter efficiency decreased when the deposit layer covered the entire surface of pre-filter, and after a few hours the periodical rinsing of nets by acid solution should be carried-out. The removal of formed deposit (rinsing by $\mathrm{HCl}$ solutions) would not result in the membrane wettability.

The above-described solution was used for study of water desalination by MD process. The SEM investigations confirmed that the amount of deposit formed within the interior of MD module was significantly reduced when the filter element was assembled at the module inlet (Figure 7). 

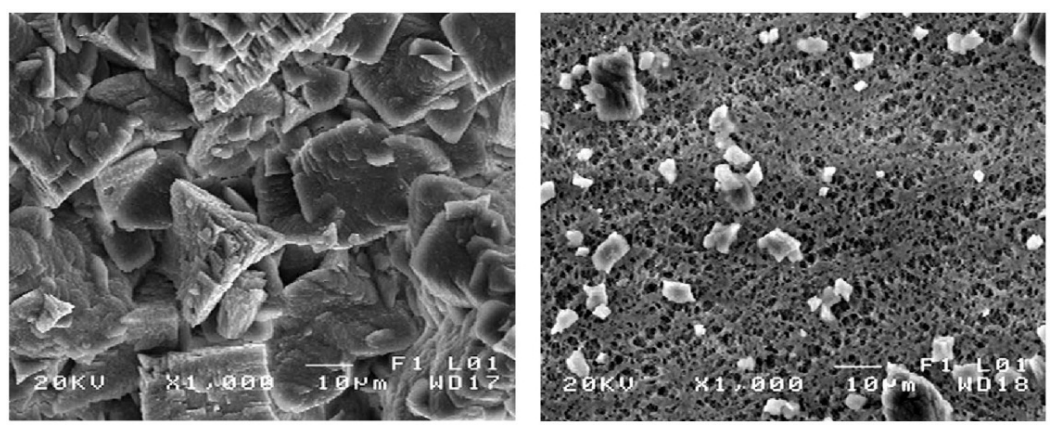

Figure 7. SEM images of membrane surface after $50 \mathrm{~h}$ desalination of tap water by MD process. A) MD module without pre-filter nets; B) MD module combined with pre-filter nets element.

The net filter worked as a heterogeneous crystallizer and a large amount of the $\mathrm{CaCO}_{3}$ was deposited on the net surfaces (Figure 8). A periodical removal of the deposit by rinsing with diluted $\mathrm{HCl}$ solutions did not cause the membrane wettability [30]. This creates the possibility of application rinsing with acid to restrict a decline of MD installation efficiency during desalination of effluents containing the bicarbonate ions.

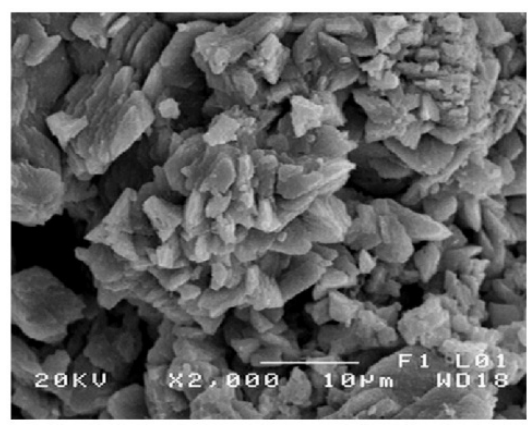

Figure 8. $\mathrm{SEM}$ image of $\mathrm{CaCO}_{3}$ deposit formed on the nets surface inside the pre-filtration element during MD process of tap water.

The concentration of effluents can be also carried out with a cyclic removal of deposits formed on the membrane surface. However, this should be performed with a sufficient frequency, so that the formed crystals will penetrate the membrane wall in the least degree. In Figure 9 was shown the membrane with deposit precipitated during MD of the geothermal water, subjected to the concentration from 120 to $286 \mathrm{~g} \mathrm{NaCl} / \mathrm{dm}^{3}$. The crystallization of calcium sulphate was observed when the concentration of sulphates achieved a level of 2.4-2.6 $\mathrm{g} \mathrm{SO}_{4}{ }^{2-} / \mathrm{dm}^{3}$. The SEM-EDS line analysis of membrane cross-section demonstrated that significant scale amounts were found up to the depth of $80-100 \mu \mathrm{m}$ inside the membrane wall (Figure 10). Therefore, the crystals of $\mathrm{CaSO}_{4}$ can damage the thin walls of capillary mem- 
branes. However, the fresh geothermal water dissolved the $\mathrm{CaSO}_{4}$ deposit from the membrane surface. Using a batchwise mode of feeding the MD installation, the concentration of geothermal water was carried out over $800 \mathrm{~h}$, without a significant loss of efficiency of used MD module [31].
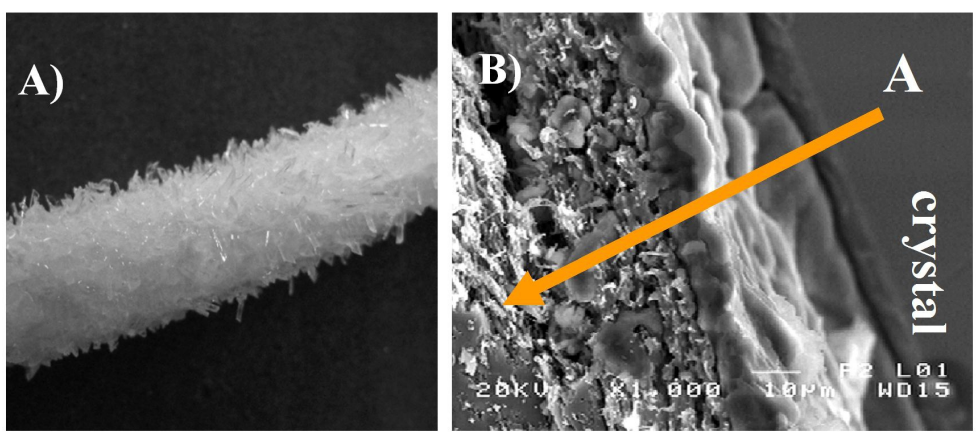

Figure 9. SEM images of $\mathrm{CaSO}_{4}$ deposited on the membrane surface during geothermal water concentration by MD process. A) external surface of capillary Accurel PP V8/2 HF membrane; B) cross-section of membrane with salt deposit.

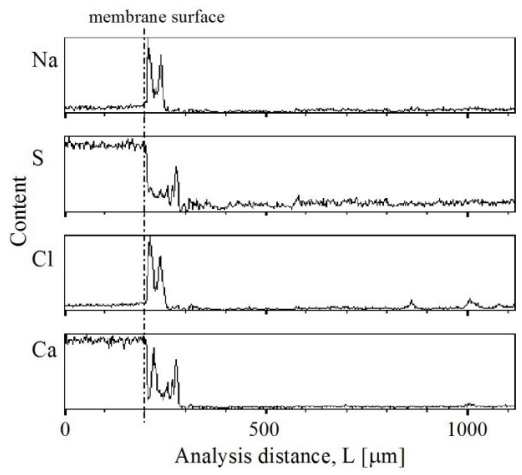

Figure 10. The results of SEM-EDS line analysis (direction A from Figure 9B).

A long-term exploitation of the MD module with a periodical removal of deposits formed on the membrane surface may result in the membrane degradation. The SEM image of the membranes used over a period of several months for water demineralisation was shown in Figure 11. The formed deposit of $\mathrm{CaCO}_{3}$ was removed at every $50-100 \mathrm{~h}$ by a periodical rinsing of module with 3-5 wt $\% \mathrm{HCl}$ [32]. A thickness of damaged membrane did not exceed $50 \mu \mathrm{m}$, however, the MD process could be still operate because the total thickness of the membrane amounted $400 \mu \mathrm{m}$. Moreover, the obtained results unequivocally demonstrated that the application of methods allowed to restrict the scaling intensity of MD membranes is recommended. 


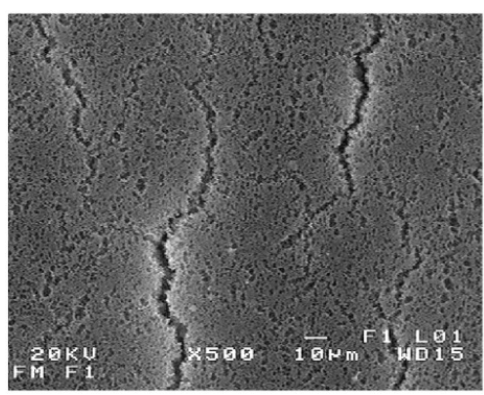

Figure 11. SEM image of the surface of Accurel PP S6/2 membrane degraded as a result of $\mathrm{CaCO}_{3}$ scaling (periodical removal by $\mathrm{HCl}$ solution).

A continuous concentration of the saturated $\mathrm{NaCl}$ solutions was successfully carried out in a MD installation integrated with the three-stages crystallizer (Figure 12). The amount of salt separated in the crystallizer was varied in the range of $20-102 \mathrm{~kg} \mathrm{NaCl} / \mathrm{m}^{2} 24 \mathrm{~h}$, and was found to be dependent on the feeding solution concentration as well as on the quantity of water removed from the brine in the MD process [14].

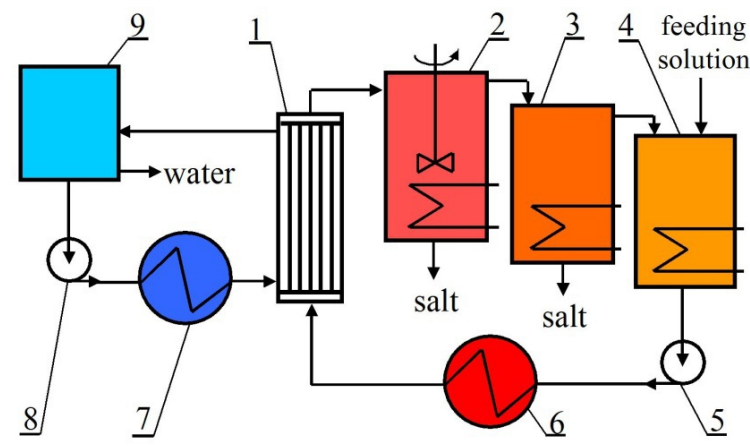

Figure 12. The experimental set-up for DCMD integrated with crystallizer. 1 - MD module, 2, 3, 4 - crystallisation system, 5, 8 - pump, 6 - heating system, 7 - cooling system, 9 - distillate reservoir.

\section{Effluents treatment}

Water is a solvent commonly used in various technological processes. After the separation of products, the technological operations generate the effluents containing the residues of products and the raw materials. In many cases such effluents after the treatment and supplementation with raw materials could be recycled to the technological process. The accumulation of waste products and salts in these effluents often preclude such solutions. Therefore, 
the removal of these substances by the methods of selective separation would allow to eliminate this restriction.

The effluents generated during the process of ethanol production constitute the example of such effluents. A significant amount of wastewater discharged from the distillation column (stillage) creates a serious ecological problem. The membrane processes enables the removal of biomass and salts from the post-reaction streams, and such treated effluents can be reused in the bioreactors. Wastewater poses a threat to the environment and must be managed, which leads to a significant increase in the energy consumption during the process of ethanol production. The energy cost is the second largest factor in ethanol production next to the costs of raw material consumption. The majority of energy is used for broth distillation that contains only $5-12 \%$ ethanol after completing the sugar fermentation process [33, 34].

An increase in the ethanol concentration would lower the cost of distillation, but it is difficult to achieve higher concentrations in the classic feed-batch fermentation due to the inhibition phenomena $[35,36]$. Another serious problem is associated with large volume of wastewater discharged from the distillation column (stillage). One of the primary methods used in stillage management is the concentration by evaporation and subsequently drying in order to prepare a protein additive for animal feeding. The condensates produced from stillage evaporation process constitute low-polluted water, and can be recycled as dilution water for the fermentation step. The recycling or reuse of low-contaminated wastewater after an appropriate treatment allows to limit its environmental impact. The major drawback is the presence of compounds, such as aliphatic acids (formic, acetic, propionic, butyric, valeric and hexanoic), alcohols (2,3-butanediol), aromatic compounds (phenyl-2-ethyl-alcohol) and furane derivatives (furfural), which inhibit the fermentation [36]. A substantial part of these compounds can be removed by the treatment of condensate with reverse osmosis [36, 37].

The above problems can be successfully solved by reduction of the amounts of stillage, which can be achieved by the application of membrane bioreactors for ethanol production $[38,39]$. The membrane separation retains the yeast cells in the bioreactor, which facilitates the distillation of ethanol from the obtained filtrate (Figure 13).

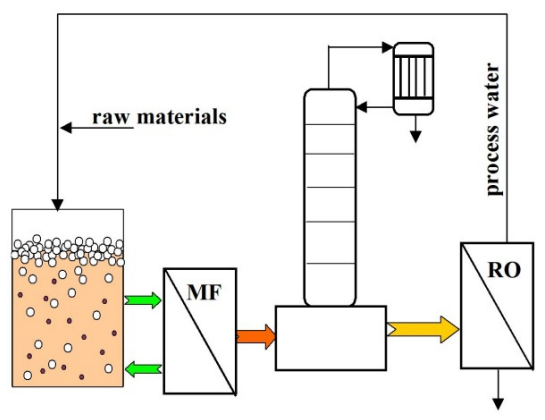

Figure 13. Continuous membrane bioreactor with process water re-use system. 
A continuous dosing of the substrates and an increase of the yeast concentration in the broth improves the productivity and efficiency of the bioreactor. Microfiltration (MF) is usually used as the separation method, although it does not reduce the amount of effluents produced during ethanol distillation. However, a clear solution of ethanol without any microorganisms was obtained after the MF process, and the expensive process of stillage evaporation is no longer necessary. After the removal of organic acids e.g. by reverse osmosis [36], such solution can be reused as the technological water in the fermentation process.

Moreover, a continuous fermentation is more attractive than the batch process due to its higher productivity, better process control and improved yields [40-42]. The challenge is how to effectively remove the yeast-produced metabolites from the broth. The use of MD (Figure 14) for the removal of ethanol and other volatile metabolites from broth will both decrease the inhibitory effect of these compounds on microbial culture and reduce the costs of further concentration of alcohol [43].

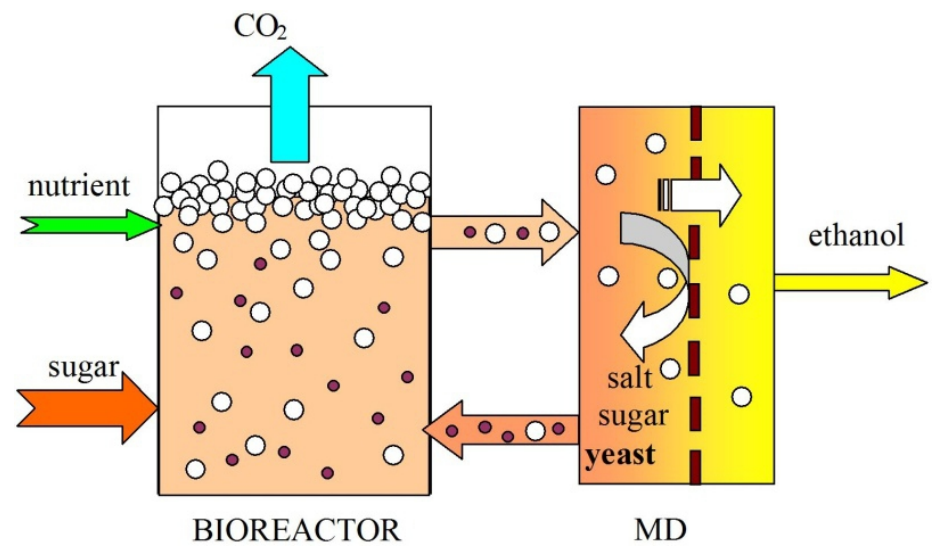

Figure 14. Ethanol production in membrane bioreactor integrated with MD process.

In the case of ethanol production in the MD bioreactor, the concentration of obtained distillate (the enrichment coefficient) is a more important parameter than the magnitudes of permeate flux. The higher the enrichment coefficient, the lower the costs associated with further concentration of the alcohol solution. The results of MD treatment of the fermenting broth were markedly different from the separation of standard solutions of ethanol. During the experiments, the ethanol concentration in the broth varied in the range 20-50 g EtOH/ $\mathrm{dm}^{3}$. The obtained enrichment coefficient amounted to 8-12, and it was two-fold higher than that obtained for the standard solutions of ethanol. It was found that bubbles of the $\mathrm{CO}_{2}$ formed during the fermentation had a significant influence on the results [44]. Due to the presence of the bubbles forming a layer adjacent to the membrane, the layer is enriched in alcohol, which affects the separation result during MD process. 
The main advantage of MD over conventional distillation processes is that the membrane distillation takes place at a temperature below the normal boiling point of broth solutions. The major requirement of MD process is that the used membranes must not be wetted by treated solutions. The performed studies demonstrated that the broth subjected to the separation did not affect the hydrophobic properties of the polypropylene membrane assembled in the MD modules. Moreover, the MD process was successfully applied for a long-term study to remove the volatile components from the fermentation broth. Besides ethanol, propionic and acetic acids were transferred from the broth to the distillate [43, 44]. Therefore, the course of the fermentation carried out in the membrane distillation bioreactor considerably accelerates the fermentation rate and increases the efficiency by a selective removal of the fermentation products.

A selective separation of ethanol only has the effect of increasing the concentration of other metabolites and substrates that have not been used. It creates an unfavourable reaction environment for yeast and, as a result, suddenly decreases the number of yeast cells and fermentation efficiency after a few dozen hours [45]. In such case, besides a selective removal of separated volatile metabolites a part of broth (bleeding method) should be also removed from the bioreactor. The collected solution can be subjected to the classical distillation (ethanol removal), and the obtained stillage can be further treated with the use of MF process followed by NF. The NF permeate can be recycled into the bioreactor (Figure 15).

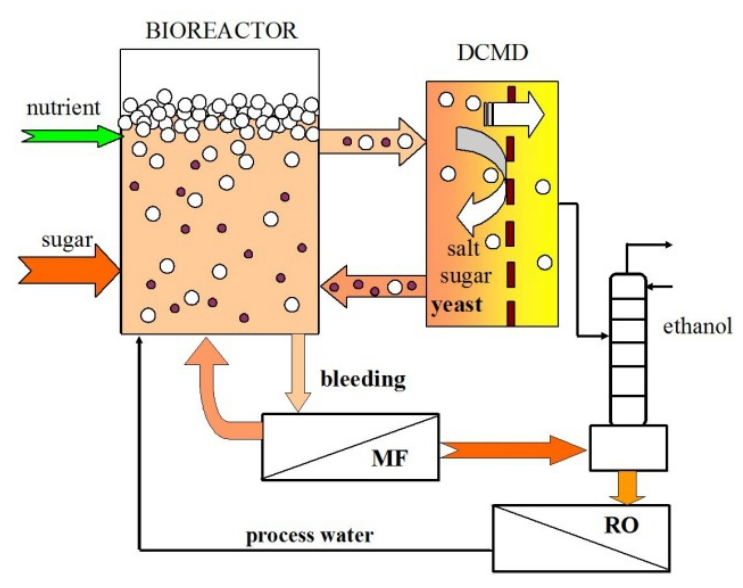

Figure 15. Integrated membrane system for continuous ethanol production with effluents treatment.

The MF is often utilized for the purification and sterilization of various biological solutions, including fermentation broths [46]. However, fouling causes a decrease of permeate flux resulting from growing resistance of membrane, hence, a deterioration of efficiency of processes and finally, shortening the membrane life (Figure 16). 


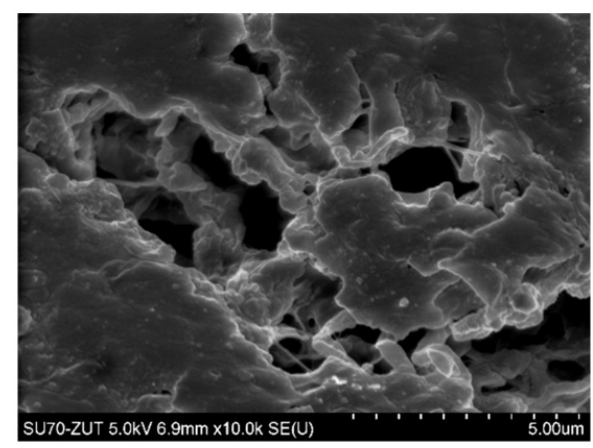

Figure 16. SEM image of deposit formed on the membrane surface during the MF process of broth.

It was demonstrated that when the filtered effluents contains only the particles larger than the membrane pores, the main mechanisms of fouling is a pore clogging and the formation of filter cake [47]. The removal of fouling deposits requires the chemical cleaning, the objective of which is to restore the permeability and selectivity of the membranes process while preserving the hygienic conditions of operation [48]. The used cleaning agents clean the membrane through the removal of foulants, change in their morphology or a modification of properties of fouling layer (Figure 17). It was found that the effectiveness of chemical cleaning depends on several factors including: temperature, $\mathrm{pH}$, cleaning agents concentration, residence time of cleaning solution in a module and the operating conditions such as crossflow velocity and the transmembrane pressure [49].

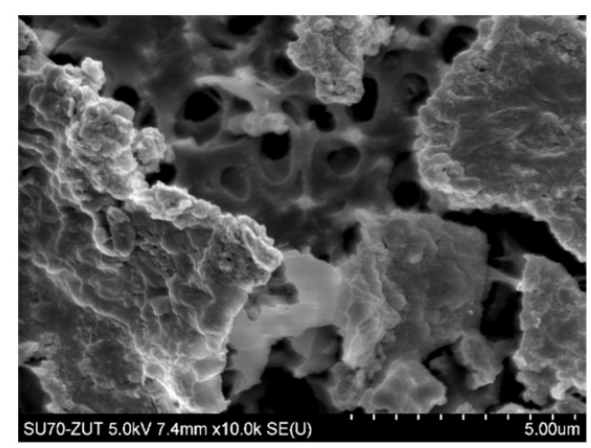

Figure 17. SEM image of membrane surface after chemical cleaning of MF module.

The literature review reveals that it is more advantageous to use the ceramic membranes instead of the polymeric membranes, because they exhibit high mechanical and chemical resistance [50]. This enables the operation of ceramic module under high pressures and the application of backflush, and offers the resistance on extremely high temperatures and concentrations $[50,51]$. 
The MF process of yeast suspensions was carried out using a single-channel ceramic membrane and the polypropylene membrane with similar dimensions of the pores $(0.2 \mu \mathrm{m})$. The changes of the values of relative fluxes during the broth separation were shown in Figure 18.

In the case of MF with the use polymeric membrane, a decline of the permeate flux was a slightly lower. After completing the MF process studies, the determination of decline of maximum permeates flux was performed. It was found, that the maximal permeate flux for the ceramic membrane decreased to $30 \%$ of the initial value after performing MF of yeast suspension for $120 \mathrm{~min}$. This flux decline was larger by about $10 \%$ in comparison with that obtained for the polymeric membrane. After completing the microfiltration process, the installation was rinsed with water several times, what allowed to remove the majority of suspensions from the installation. Subsequently, the permeate flux for clean water was checked in order to determine the actual efficiency of the membranes. This procedure allowed to determine a decline of maximal permeates flux after completed stage of the studies. The maximum permeate flux for the ceramic membrane decreased to $40 \%$ of the initial value after performing the microfiltration of yeast suspension for $180 \mathrm{~min}$. This flux decline was larger by about $20 \%$ in comparison with that for the polymeric membrane.

In order to compare the effectiveness of used chemical cleaning of both membranes, the same cleaning procedure was used: rinsing the installation with water, rinsing with $1 \%$ solution of sodium hydroxide for $20 \mathrm{~min}$ followed by rinsing with $0.5 \%$ solution of orthophosphoric acid (20 min). The application of chemical cleaning enabled the restoration of the initial efficiency for the polymeric membrane almost in $100 \%$, contrary to that was observed in the case of ceramic membrane (Figure 19). Based on this fact it was concluded, that the ceramic membrane requires a long cleaning process, what affects adversely the costs of membrane process with the use of ceramic membranes.

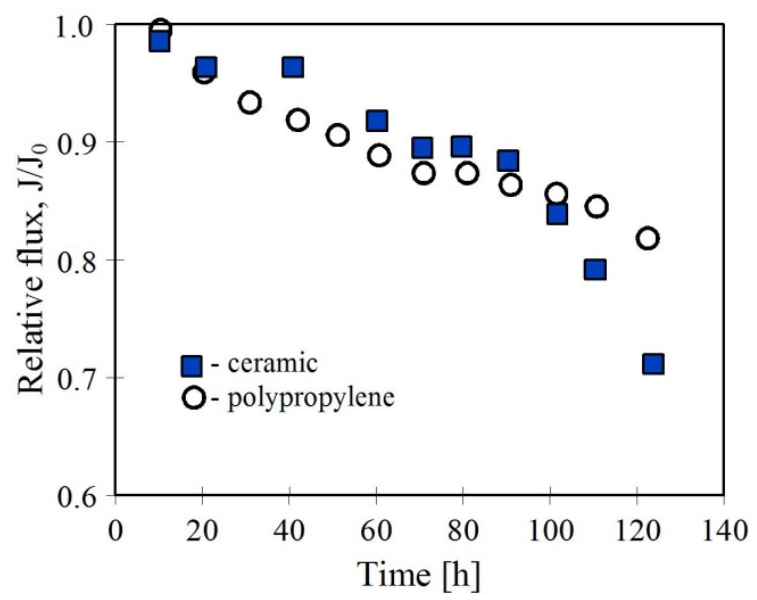

Figure 18. Changes of the relative fluxes obtained during MF of yeast solution ( $3 \mathrm{~g} / \mathrm{L}$ ) with ceramic and polypropylene membranes. 


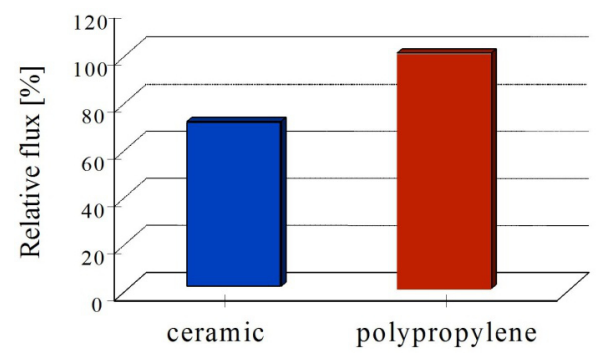

Figure 19. The results of chemical cleaning of polypropylene and ceramic membrane.

The chemical cleaning of ceramic membrane was repeated 4 times, however, the expected results were not achieved. Further studies demonstrated that after the separation of biological solutions the highest effectiveness of ceramic membrane cleaning was achieved as a result of using multi-stage cleaning procedure involving chemical cleaning - alkaline and acidic and back flushing.

\section{Conclusions}

The industrial effluents can contain small amounts of impurities, hence, their recirculation to the technological process is hindered. With regard to this, these effluents constitute a wastewater, which are often dangerous to the environment. In many cases, solutes (e.g. $\mathrm{NaCl}$ ) contained in these effluents are not poisonous, however, their excessive amount renders their disposal into the environment impossible. The removal of these components can transform the industrial effluents from waste into the reusable raw materials.

The membrane processes, especially in the form of integrated systems, allows to treat even a complex effluents. Moreover, their application allows to modify the technology, and as a result, the amount of generated wastewater will be significantly reduced.

\section{Acknowledgements}

The Polish State Committee for Scientific Research is acknowledged for the support of this work (2009-2012).

\section{Author details}

Marek Gryta*

Address all correspondence to: marek.gryta@zut.edu.pl

West Pomeranian University of Technology, Szczecin, Poland 


\section{References}

[1] Drioli, E., \& Romano, M. (2001). Progress and new perspectives on integrated membrane operations for sustainable industrial growth. Industrial \& Engineering Chemistry Research, 2001;40(5) , 1277-1300.

[2] Singh, R. (2006). Hybrid membrane systems for water purification. Oxford: Elsevier.

[3] Günder, B. (2001). The membrane-coupled activated sludge process in municipal wastewater treatment. Lancaster: Technomic.

[4] Schorr, M. editor. (2011). Desalination, trends and technologies. Rijeka: InTech.

[5] Nunes, S. P., \& Peinemann, K. V. editors. (2006). Membrane technology in the chemical industry. Weinheim: Wiley; 2006.

[6] Gryta, M., Tomaszewska, M., Morawski, A. W., \& Grzechulska, J. (2001). Membrane distillation of $\mathrm{NaCl}$ solution containing natural organic matter. Journal of Membrane Science, 181(2), 279-287.

[7] Curcio, E., Ji, X., Di Profio, G., Sulaiman, A. O., Fontananova, E., \& Drioli, E. (2010). Membrane distillation operated at high seawater concentration factors: Role of the membrane on $\mathrm{CaCO}_{3}$ scaling in presence of humic acid. Journal of Membrane Science, 346(2), 263-269.

[8] Gryta, M. (2002). Direct contact membrane distillation with crystallization applied to $\mathrm{NaCl}$ solutions. Chemical Papers, 56(1), 14-19.

[9] Teoh, M. M., Bonyadi, S., \& Chung, T. S. (2008). Investigation of different hollow fiber module designs or flux enhancement in the membrane distillation process. Journal of Membrane Science, 2008;311(1-2) , 371-379.

[10] Mericq, J. P., Laborie, S., \& Cabassud, C. (2010). Vacuum membrane distillation of seawater reverse osmosis brines. Water Research, 44(18), 5260-5273.

[11] El-Bourawi, M. S., Ding, Z., Ma, R., \& Khayet, M. (2006). A framework for better understanding membrane distillation separation process. Journal of Membrane Science, 2006;285(1-2) , 4-29.

[12] Gryta, M., Karakulski, K., Tomaszewska, M., \& Morawski, W. (2006). Demineralization of water using a combination of MD and NF(RO). Desalination, 2006;200(1-3) 451-452.

[13] Karakulski, K., \& Gryta, M. (2005). Water demineralisation by NF/MD integrated processes. Desalination, 2005;177(1-3) , 109-119.

[14] Gryta, M. (2002). Concentration of $\mathrm{NaCl}$ solution by membrane distillation integrated with crystallisation. Separation and Purification Technology , 37(15), 3535-3558. 
[15] Karakulski, K., Gryta, M., \& Sasim, M. (2006). Production of process water using integrated membrane processes. Chemical Papers, 60(6), 416-421.

[16] Gryta, M., Karakulski, K., Tomaszewska, M., \& Morawski, A. (2005). Treatment of effluents from the regeneration of ion exchangers using the MD process. Desalination, 2005;180(1-3) , 173-180.

[17] Qu, D., Wang, J., Wang, L., Hou, D., Luan, Z., \& Wang, B. (2009). Integration of accelerated precipitation softening with membrane distillation for high-recovery desalination of primary reverse osmosis concentrate. Separation and Purification Technology, 67(1), 21-25.

[18] Tomaszewska, M., Gryta, M., \& Morawski, A. W. (2001). Recovery of hydrochloric acid from metal pickling solutions by membrane distillation. Separation and Purification Technology, 2001; 22-23, 591-600.

[19] Oluji, Ž., Behrens, M., Sun, L., \& Fakhri de Graauw, J. (2010). Augmenting distillation by using membrane based vapor-liquid contactors: An engineering view from Delft. Journal of Membrane Science, 2010;350(1-2) 19-31.

[20] Macedonio, F., \& Drioli, E. (2008). Pressure-driven membrane operations and membrane distillation technology integration for water purification. Desalination, 2008;223(1-3) , 396-409.

[21] Gryta, M. (2009). $\mathrm{CaSO}_{4}$ scaling in membrane distillation process. Chemical Papers, 63(2), 146-151.

[22] Sheikholeslami, R. (2007). Fouling in membranes and thermal units. L'Aquila: Balaban Desalination Publications.

[23] Gryta, M. (2008). Alkaline scaling in the membrane distillation process. Desalination, 2008;228(1-3) , 128-134.

[24] Gryta, M. (2008). Fouling in direct contact membrane distillation. Journal of Membrane Science, 325(1), 383-394.

[25] Gryta, M. (2010). Application of membrane distillation process for tap water purification. Membrane Water Treatment, 1(1), 1-12.

[26] Gryta, M. (2008). Chemical pretreatment of feed water for membrane distillation. Chemical Papers, 62(1), 100-105.

[27] Gryta, M. (2012). Polyphosphates used for membrane scaling inhibition during water desalination by membrane distillation. Desalination, 285(1), 170-176.

[28] Gryta, M. (2010). Desalination of thermally softened water by membrane distillation process. Desalination, 2010;257(1-3) , 30-35.

[29] Gryta, M. (2011). The influence of magnetic water treatment on $\mathrm{CaCO}_{3}$ scale formation in membrane distillation process. Separation and Purification Technology, 80(2), 293-299. 
[30] Gryta, M. (2009). Scaling diminution by heterogeneous crystallization in a filtration element integrated with membrane distillation module. Polish Journal of Chemical Technology, 11(2), 60-65.

[31] Gryta, M., \& Palczyński, M. (2011). Desalination of geothermal water by membrane distillation. Membrane Water Treatment , 2(3), 147-158.

[32] Gryta, M. (2005). Long-term performance of membrane distillation process. Journal of Membrane Science, 2005;265(1-2) , 153-159.

[33] Demirbas, A. (2007). Progress and recent trends in biofuels. Progress in Energy and Combustion Science, 2007;33, 1-18.

[34] Bai, F. W., Anderson, W. A., \& Moo-Young, M. (2008). Ethanol fermentation technologies from sugar and starch feedstocks. Biotechnology Advances, 26(1), 89-105.

[35] Sassner, P., Galbe, M., \& Zacchi, G. (2008). Techno-economic evaluation of bioethanol production from three different lignocellulosic materials. Biomass and Bioenergy, 32(5), 422-430.

[36] Morin-Couallier, E., Payot, L. T., Pastore, Bertin. A., \& Lameloise, M. L. (2006). Recycling of distillery effluents in alcoholic fermentation. Applied Biochemistry and Biotechnology, 133(3), 217-238.

[37] Morin-Couallier, E., Salgado-Ruiz, B., Lameloise, M. L., \& Decloux, M. (2006). Usefulness of reverse osmosis in the treatment of condensates arising from the concentration of distillery vinasses. Desalination, 2006;196(1-3) , 306-317.

[38] Takaya, M., Matsumoto, N., \& Yanase, H. (2002). Characterization of membrane bioreactor for dry wine production. Journal of Bioscience and Bioengineering, 93(2), 240-244.

[39] Park, B. G., Lee, W. G., Chang, Y. K., \& Chang, H. N. (1999). Long-term operation of continuous high cell density culture of Saccharomyces cerevisiae with membrane filtration and on-line cell concentration monitoring. Bioprocess Engineering, 21(2), 97-100.

[40] Choi, G.-W, Kang, H.-W., \& Moon, S.-K. (2009). Repeated-batch fermentation using flocculent hybrid, Saccharomyces cerevisiae CHFY0321 for efficient production of bioethanol. Applied Microbiology and Biotechnology, 84(2), 261-269.

[41] Kargupta, K., Datta, S., \& Sanyal, S. K. (1998). Analysis of the performance of a continuous membrane bioreactor with cell recycling during ethanol fermentation. Biochemical Engineering Journal, 1(1), 31-37.

[42] Park, B. G., Lee, W. G., Chang, Y. K., \& Chang, H. N. (1999). Long-term operation of continuous high cell density culture of Saccharomyces cerevisiae with membrane filtration and on-line cell concentration monitoring. Bioprocess Engineering, 21(2), 97-100. 
[43] Barancewicz, M., \& Gryta, M. (2012). Ethanol production in a bioreactor with an integrated membrane distillation module. Chemical Papers, 66(2), 85-91.

[44] Gryta, M. (2001). The fermentation process integrated with membrane distillation. Separation and Purification Technology, 2001;24(1-2) , 283-296.

[45] Gyamerah, M., \& Glover, J. (1996). Production of ethanol by continuous fermentation and liquid-liquid extraction. Journal of Chemical Technology and Biotechnology, 66(2), 145-152.

[46] Sondholi, R., \& Bhave, R. (2001). Role of backpulsing in fouling minimization in crossflow filtration with ceramic membranes. Journal of Membrane Science , 186(1), 41-52.

[47] Stopka, J., Bugan, S. G., Broussous, L., Schlosser, S., \& Larbot, A. (2001). Microfiltration of yeast suspensions through stamped ceramic membranes. Separation and Purification Technology, 2001;25(1-3) , 535-543.

[48] Bird, M. R., \& Bartlett, M. (2002). Measuring and modelling flux recovery during the chemical cleaning of MF membranes for the processing of whey protein concentrate. Journal of Food Engineering, 53(2), 143-152.

[49] Blanpain-Avet, P., Migdal, J. F., \& Benezech, T. (2009). Chemical cleaning of a tubular ceramic microfiltration membrane fouled with a whey protein concentrate suspension-Characterization of hydraulic and chemical cleanliness. Journal of Membrane Science, 2009;337(1-2) , 153-174.

[50] Hofs, B., Ogier, J., Vries, D., Beerendonk, E. F., \& Cornelissen, E. R. (2011). Comparison of ceramic and polymeric membrane permeability and fouling using surface water. Separation and Purification Technology, 79(3), 365-374.

[51] Kim, J., \& Van Der Bruggen, B. (2010). The use of nanoparticles in polymeric and ceramic membrane structure: Review of manufacturing procedures and performance improvement for water treatment. Environmental Pollution, 158(7), 2335-2349. 
